\title{
Activated seismicity by strain rate change in the Yaeyama region, south Ryukyu
}

\author{
Mamoru Nakamura* ${ }^{*}$ and Ayumi Kinjo
}

\begin{abstract}
We evaluated the long-term strain rate by using continuous global navigation satellite system data of GEONET and compared it with seismicity activation between 1996 and 2017 near Iriomote Island, south Ryukyu arc. We analyzed the seismicity by using the epidemic-type aftershock sequence model to detect the timing when the seismicity had changed. The results revealed that the long-term shear strain rate had increased on around 2002 and around 2013, and this was accompanied by an increase in seismicity in both 2002 and 2013. The change in the shear strain rate in 2002 could be explained by the crustal movement induced by the 2002 afterslip in the area west of Iriomote Island. The change in the shear strain rate in 2013 could be explained by the post-seismic crustal movement induced by the dike intrusion that occurred during the earthquake swarm in the Okinawa Trough in April 2013. These findings suggest that the long-term seismicity near Iriomote Island is strongly affected by changes in the crustal strain rate, which have occurred in the past in response to dike intrusions in the Okinawa Trough and slow earthquakes in the Ryukyu Trench.
\end{abstract}

Keywords: Seismicity change, Strain rate change, Slow slip event, ETAS, Ryukyu arc

\section{Introduction}

Faulting during a slow earthquake changes the stress distribution and can induce surrounding seismicity. This makes it possible to estimate the stress change near the fault of a silent slip. Earthquake swarms have occurred in conjunction with slow events in the detachment fault beneath Kilauea's south flank on Hawaii Island (Dieterich et al. 2000; Segall et al. 2006; Wolfe et al. 2007). In the Boso region, central Japan, earthquake swarms have been generated repeatedly when slow slip events (SSEs) occurred in the subducting Pacific plate (Ozawa et al. 2007). The moment magnitude of the studied SSEs was $\sim$ Mw 6.5, whereas the maximum magnitude of the swarm was $\mathrm{Mw} \sim 4$ (Ozawa et al. 2007). This finding suggests that the plate interface mainly slips aseismically, whereas small seismic patches ruptured during the slip of the Mw 6.5 aseismic events. The seismicity of the swarm accompanying the SSEs had notable characteristics in that the background

*Correspondence: mnaka@sci.u-ryukyu.ac.jp

Faculty of Science, University of the Ryukyus, Nishihara-cho, Okinawa, Japan seismicity increased during the swarm but the aftershock productivity did not change (Llenos et al. 2009; Okutani and Ide 2011).

Various types of slow earthquakes, which can change the strain distribution, occur in the Yaeyama Islands, south Ryukyu arc. In the Yaeyama Islands, the Philippine Sea plate $(\mathrm{PH})$ is subducting beneath the Eurasian plate (EU) at a rate of $8.6 \mathrm{~cm}$ year $^{-1}$ northwestward (Bird 2003; Kreemer et al. 2014) (Fig. 1a). Because of the rifting of the Okinawa Trough at a rate of $3.5 \mathrm{~cm}$ year $^{-1}$ (Nakamura 2004; Kreemer et al. 2014) (Fig. 1b), the relative convergence rate of the $\mathrm{PH}$ with respect to the Yaeyama Islands is $11.1 \mathrm{~cm}$ year ${ }^{-1}$. The depth of the subducting plate is $40-60 \mathrm{~km}$ beneath Iriomote Island (Fig. 1b). The repeating SSEs occur beneath Iriomote Island biannually (Heki and Kataoka 2008; Tu and Heki 2017). The average moment magnitude of the SSEs is 6.7. A Mw 7.4 afterslip occurred beneath the area west of Iriomote Island after the $\mathrm{Mj} 7.0$ earthquake on March 31, 2002 (Nakamura 2009). This afterslip lasted approximately $4-5$ years.

Regular crustal earthquakes are active near Iriomote Island in the central Yaeyama Islands and in the Okinawa 
Trough. Iriomote Island is located in the central part of the seismic network of the Yaeyama Islands, and the seismicity at Iriomote Island has been continuously active. The maximum magnitude $(\mathrm{Mj})$ since January 1, 1991, was 5.6, and this occurred on March 2, 2018, at Iriomote Island. Conspicuous earthquake swarms occurred from 1991 to 1994 in the area northwest of Iriomote Island, and the maximum magnitude during this time was 5.1. On December 18, 2001, Mj 7.3 normal-faulting earthquakes (Eq1) occurred south of Yonaguni Island (Fig. 2). This event was accompanied by an afterslip that lasted 1 month, and its released moment was approximately $30 \%$ of the mainshock (Nakamura 2009). In the Okinawa Trough, earthquake swarms occur every several years, and these are accompanied by M5 class earthquakes. The major swarm activities since 1990 occurred during June 1996, October 2002 (SW1), and April 2013 (SW2) (Fig. 2).

Seismicity activation was observed to have occurred after a change in the crustal movement twice since 1995 in the Yaeyama Islands. Such seismicity activation was observed in the $\mathrm{S}$ region, which is located in the central part of the Yaeyama Islands, during 2002 and 2013 (Figs. 2, 3a). The temporal seismicity activation by the aftershocks was obvious for the seismicity of $M>2.0$ in the $\mathrm{N}$ region. However, conspicuous seismic activity around the same time as the seismicity activation of the $\mathrm{S}$ region was not found in the seismicity for $M>2.5$. When the seismicity changed, the accumulation of the slip of the repeating SSEs changed around 2002 and 2013 (Tu and Heki 2017). The accumulation of the slip was $9.3 \mathrm{~cm}_{\text {year }}{ }^{-1}$ before 2002. This increased to $10.9 \mathrm{~cm} \mathrm{year}^{-1}$ from 2002 to 2007 . After 2007 , it decreased to $6.3 \mathrm{~cm}_{\text {year }}{ }^{-1}$. It increased again to $10.2 \mathrm{~cm} \mathrm{year}^{-1}$ since 2013 . Tu and Heki (2017) proposed that the transient acceleration of the SSE rate in the Yaeyama Islands was driven by the rifting in the Okinawa Trough, which accompanied the earthquake swarm. Another factor is the afterslip that occurred in 2002. Nakamura (2009) showed that the activity of the repeating SSE was changed by the 2002 afterslip. These research results suggest that the seismicity can be changed by transient fluctuations in the crustal movement caused by dike intrusions and nearby slow earthquakes. We investigated the relationship between the long-term variation of the strain rate and the seismicity activation in the Yaeyama Islands. We then investigated the cause of the strain rate change, which could have also generated the seismicity change.

\section{Data and methods}

\section{Analysis of the long-term and short-term strain rate}

In this study, we used the global navigation satellite system (GNSS) site data of GEONET in the Ryukyu Islands, which are managed by the Geospatial Information Authority of Japan (GSI). We employed the daily solution of F3 (final) at the sites for the analysis. First, we calculated the relative position of each site against site 950498 (Fig. 4). The period in which the relative position was calculated ranged from April 1, 1997, to December 31, 2017. We computed the annual velocity of each site relative to site 950498 .

We analyzed the strain rate by using the horizontal velocity of four sites $(960749,960750,960751$, and 950500) (Fig. 4). We employed the calculation formula of Shen et al. (1996). The eastward velocity $\left(V_{x}\right)$ and northward velocity $\left(V_{y}\right)$ at each station can be expressed as follows:

$$
\left[\begin{array}{l}
V_{x} \\
V_{y}
\end{array}\right]=\left[\begin{array}{llllll}
1 & 0 & \Delta x & \Delta y & 0 & \Delta y \\
0 & 1 & 0 & \Delta x & \Delta y-\Delta x
\end{array}\right]\left[\begin{array}{l}
U_{x} \\
U_{y} \\
\tau_{x x} \\
\tau_{x y} \\
\tau_{y y} \\
\omega
\end{array}\right]+\left[\begin{array}{l}
\varepsilon_{x} \\
\varepsilon_{y}
\end{array}\right]
$$

where $U_{x}$ and $U_{y}$ are the eastward and northward horizontal velocity of a certain area, respectively. The $\tau_{x x}, \tau_{x y}$, $\tau_{y y}$ terms denote the strain rate. $\omega$ represents the angular velocity of the area of concern. The terms $\Delta x$ and $\Delta y$ represent the position of the observation site relative to the reference point. $\varepsilon_{x}$ and $\varepsilon_{y}$ are the error of the eastward and northward velocity components, respectively.

To obtain the long-term strain rate change in this region including the displacement of the SSEs, which occur repeatedly at 6-7-month intervals, we calculated the 3-year average annual velocity at each site for the east-west and north-south direction, and then, we computed the strain rate by using the above equation. The analysis of the strain rate was done from January 1998 to December 2017, and it was performed by moving the calculation interval by 1 year. Then, we calculated the dilatation rate and maximum shear strain rate by using formula (4) of Sagiya et al. (2000).

Moreover, we calculated the short-term strain rate to obtain the strain caused by SSEs and earthquakes around the Yaeyama Islands. We computed the strain rate for 3 months by moving the interval by 0.5 months. We determined the average velocity by using the relative position for every 3 months, and then, we calculated the strain rate by using the above equation.

Moreover, we calculated the strain and difference in Coulomb failure stress ( $\triangle \mathrm{CFS}$ ) (King et al. 1994) for the Eq1, 2002 afterslip, 2002 earthquake swarm (SW1), and 2013 earthquake swarm (SW2) (Table 1). We used the program "DC3D" by Okada (1992) for the calculation of 


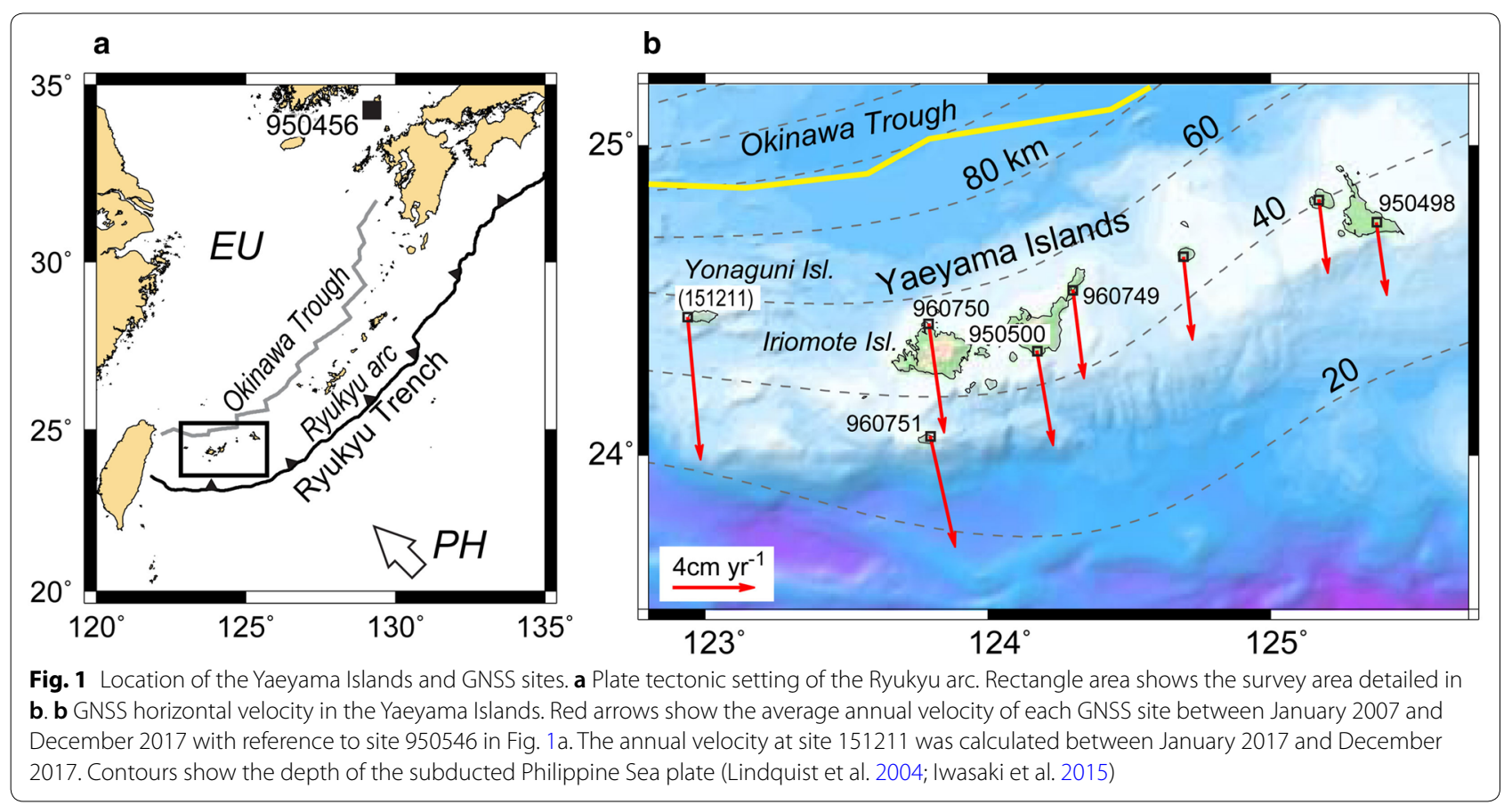

the displacement and strain field. We set the frictional coefficient of the $\triangle$ CFS to $0.0-0.6$. The fault parameters of the Eq1 were set as striking $210^{\circ}$, dipping $60^{\circ}$, slip of $150 \mathrm{~cm}$, and rake of $-120^{\circ}$. We employed the modified fault model of Nakamura (2009) for the fault model of the 2002 afterslip. We moved the fault location $30 \mathrm{~km}$ eastward, which is within the $1 \sigma$ error of the fault location. For the $S W 2$, we set the dike in the cluster of the $S W 2$, which was northwest of Iriomote Island. The length and width of the dike were set to $20 \mathrm{~km}$ and $10 \mathrm{~km}$, respectively. The opening tensile was set to $2 \mathrm{~m}$ since the volumetric change by dike intrusion was estimated as $\sim 0.4 \mathrm{~km}^{3}$ (Ando et al. 2015). For the SW1, we set the length, width, and opening tensile of the dike to the same values as those used for the SW2; this was done because the coinciding SSE obscured the displacement of the SW1 so that we could not detect it. The dike of the SW1 was set to the cluster location of the SW1, which was north of Iriomote Island. The strain axes in the Yaeyama Islands were calculated by using the horizontal displacement at four GNSS sites. The $\triangle$ CFS in the normal fault striking $135^{\circ}$ and dipping $60^{\circ}$ at the depth of $15 \mathrm{~km}$ was computed, and the results were based on the centroid moment tensor (CMT) solution in the south Ryukyu arc (Kubo and Fukuyama 2003) (Fig. 2c).

\section{Analysis of seismicity}

To determine the minimum magnitude that could be recorded completely in the $\mathrm{S}$ region, we calculated the magnitude completeness (Mc) by using the method of
Wiemer and Wyss (2000). This method compares the cumulative number of earthquakes against the magnitude, i.e., the earthquakes are sorted by magnitude, and one determines the Mc where the cumulative earthquake number does not correspond with the Gutenberg-Richter power law distribution. We used Zmap software (Wiemer 2001) for the analysis of the Mc.

We used the Japan Meteorological Agency (JMA) earthquake catalog to obtain data for January 1994 to December 2017. We used the earthquakes whose magnitudes were over 0.0 . The calculated area was located at $23.0^{\circ}-25.3^{\circ} \mathrm{N}$ and $123.0^{\circ}-124.5^{\circ} \mathrm{E}$. We set the points at every $0.05^{\circ}$ and calculated the Mc at these points. We used the earthquakes for the calculation of the Mc, which occurred within $30 \mathrm{~km}$ from each point. We computed the Mc when the number of events was over 50. The Mc was computed for an interval of 2 years between 1994 and 2017. During this period, the seismic network expanded in a stepwise manner in the Yaeyama Islands. In March 1994, the number of stations increased from two to four. In July 2000, the number of stations increased from four to six. In February 2010, the number of the stations increased from six to eight (JMA 2002, 2018). Thus, since the detection ability for earthquakes increased in March 1994, we used the data from March 1994 to December 1996 for the calculation of the Mc of 1994. The Mc values for the other terms were calculated every 2 years.

According to the results of the analysis, the Mc largely remained at 1.5-1.8 near Iriomote Island since 

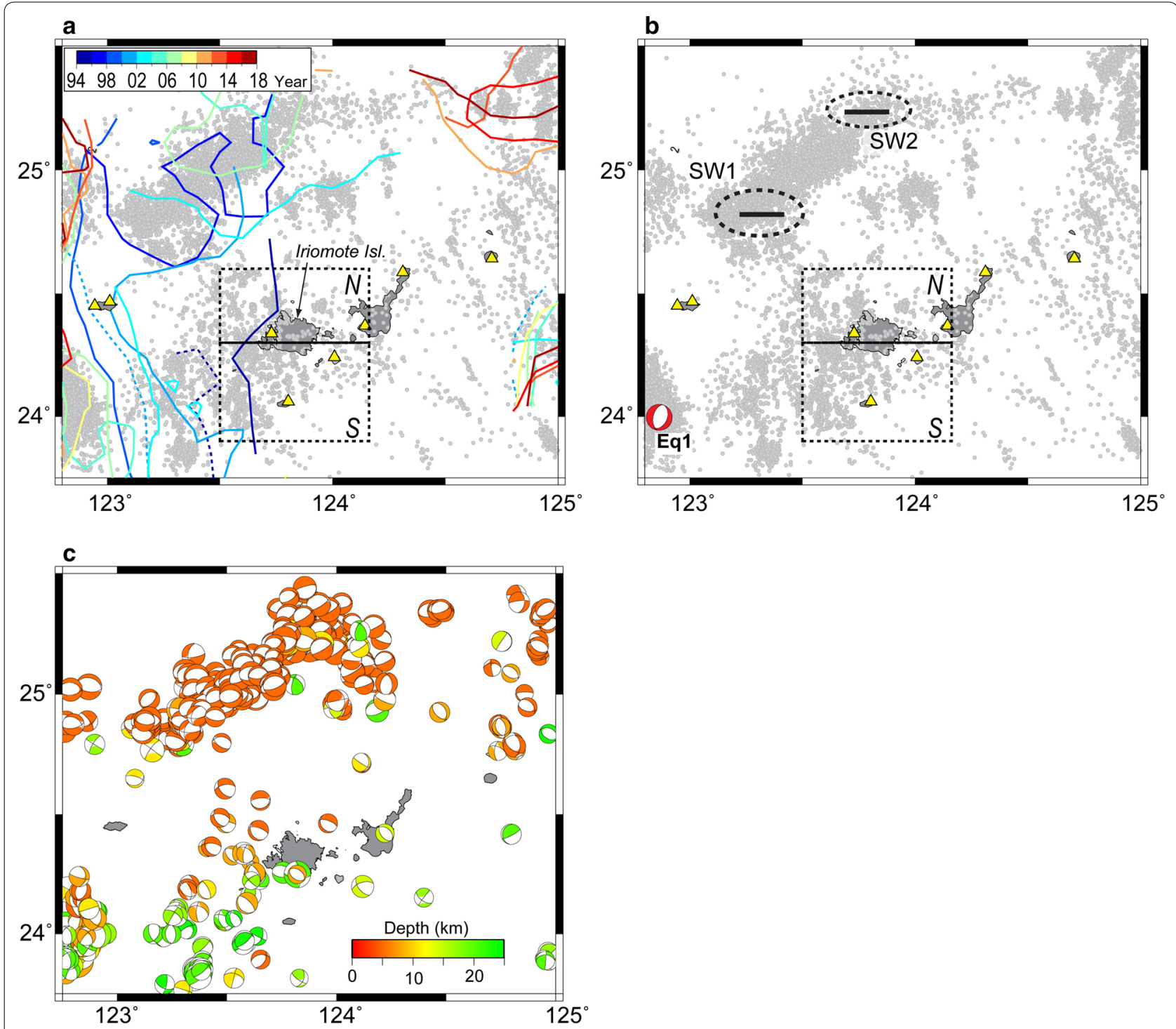

Fig. 2 Epicenter distribution of earthquakes from January 1994 to December 2017 for those with depths shallower than $30 \mathrm{~km}$ and magnitudes over 2.0. a Magnitude completeness. The solid lines show the contours where the magnitude completeness was 2.0. The dotted lines show the contours of 1994-1995 and 2000-2001 where the magnitude completeness was 2.3. The lines are colored corresponding to the initial year for the period in which the Mc was calculated. Yellow triangles show the JMA seismic stations. b Locations of earthquake swarms and large earthquakes. Dotted rectangles show the areas where the cumulative number of earthquakes is plotted in Fig. 3. The CMT solution shows the event of Eq1 (Fnet, NIED). c The CMT solutions of the earthquakes (between January 2000 and March 2018) whose depths are shallower than $20 \mathrm{~km}$. The CMT solutions of Fnet provided by NIED were plotted

1996 (Fig. 2). However, earthquake detection capabilities were insufficient between 1994 and 1995. Moreover, for Period I, the Mc increased to over 2.0 in the southwest corner of the $\mathrm{S}$ region between 2000 and 2001 (Fig. 2). However, the $\mathrm{Mc}$ in the $\mathrm{S}$ region stayed within 2.3 through Period I (Fig. 2). Thus, we set the Mc to 2.3 for the analysis of Period I. Since the Mc was within 2.0 in Period II, we set the Mc to 2.0 for the analysis of Period II (Fig. 2).
Next, we detected the timing of seismicity activation by using the ETAS (epidemic-type aftershock sequence) model (Ogata 1988, 1999). We adopted the software "etas_solve" to estimate the parameters of the ETAS model (Kasahara et al. 2016). As for the ETAS model, the seismicity $\lambda(t)$ at time $t$ can be explained as the combination of the background seismicity rate and the effect of preceding earthquakes. After normalization of the 

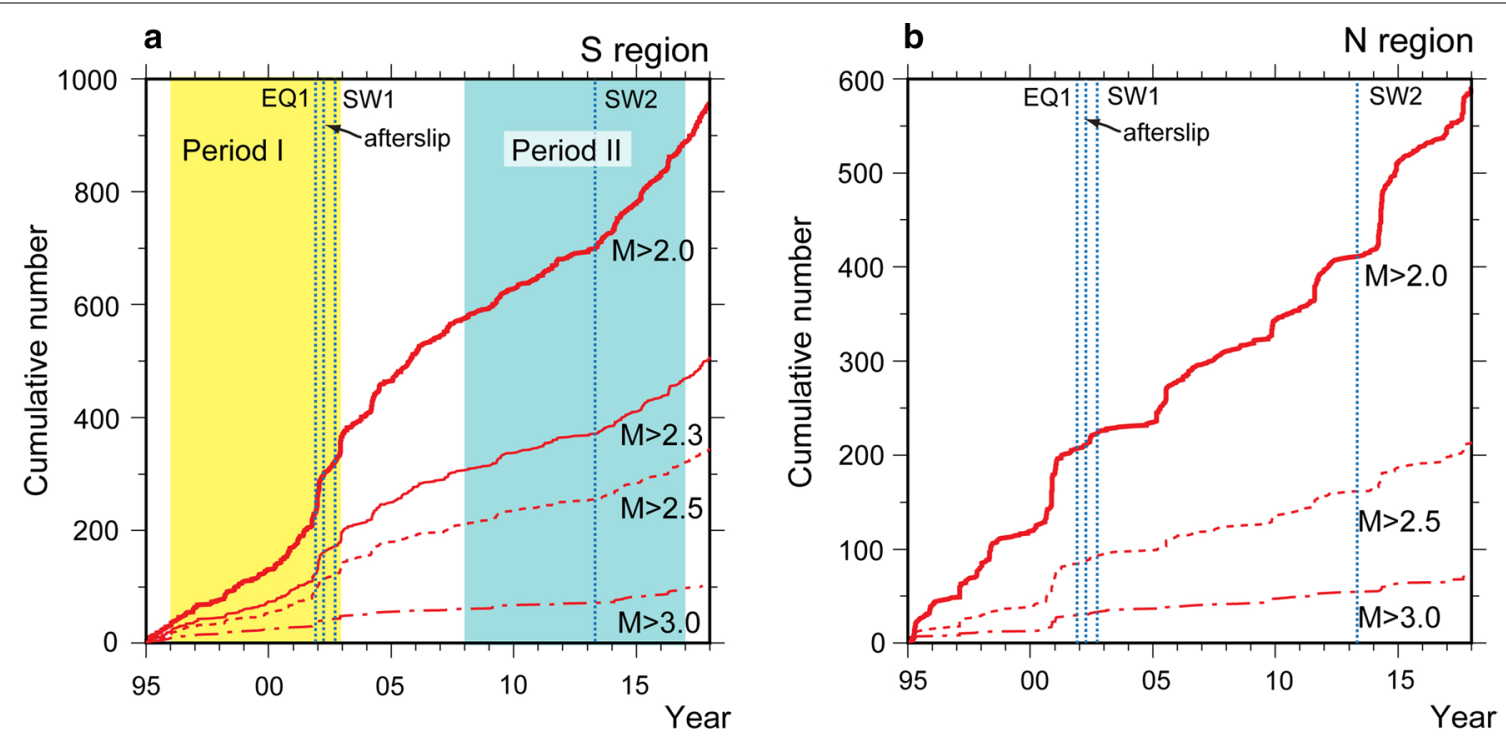

Fig. 3 Cumulative number of earthquakes since 1995 near Iriomote Island. a Cumulative number of earthquakes in the $\mathrm{S}$ region. The location of this area is shown in Fig. 2. The bold line, solid line, dotted line, and dot-dash line denote the cumulative number of earthquakes with magnitudes over 2.0, 2.3, 2.5, and 3.0, respectively. The yellow rectangle area and green rectangle area show the Period I (from January 1996 to December 2003) and Period II (January 2008 to December 2016) results, respectively. Blue dotted lines show the occurrence of the Eq1, afterslip, SW1, and SW2. b The same as a but in the $\mathrm{N}$ region

aftershock productivity $K_{\text {es }}$, the $\lambda(t)$ term in "etas_solve" can be written as follows: where $\mathrm{AIC}_{0}$ represents the $\mathrm{AIC}$ for the model of time interval $[S, T] . \mathrm{AIC}_{1}$ and $\mathrm{AIC}_{2}$ represent the $\mathrm{AIC}$ for

$$
\lambda(t)=\frac{\mu_{\mathrm{es}}}{\tau}+\sum_{t_{i}<t} \frac{K_{\mathrm{es}}}{\int_{0}^{\tau}(u+c)^{-p} \mathrm{~d} u} \exp \left(\alpha\left(M_{i}-M_{0}\right)\right) /\left(t-t_{i}+c\right)^{p}
$$

where $\mu_{\mathrm{es}}$ is the background seismicity. $\alpha$ is the effect of earthquake productivity between the mainshock and aftershocks. $K$ is the aftershock productivity. $c$ and $p$ are parameters from the Omori-Utsu law. $\tau$ is the normalized time interval, and we set $\tau$ to 1 . These five parameters were determined by using the maximum likelihood estimation method with data from the earthquake catalog (origin time: $t_{i}$ and magnitude: $M_{i}$ ). Here, $M_{0}$ means the reference magnitude. We set $M_{0}$ as 2.0.

We determined the time when the seismicity changed in around 2002 and 2013 by using Akaike information criterion (AIC) values. We compared the goodness of the fitting models in the time interval between $S$ and $T([S, T])$ with those in two intervals, namely, $\left[S, T_{0}\right]$ and $\left[T_{0}, T\right]$, and these AICs can be expressed as follows (Ogata 1992):

$$
\begin{array}{r}
\mathrm{AIC}_{0}=-2 \ln L(S, T)+2 k_{0} \\
\mathrm{AIC}_{1}=-2 \ln L\left(S, T_{0}\right)+2 k_{1} \\
\mathrm{AIC}_{2}=-2 \ln L\left(T_{0}, T\right)+2 k_{2}
\end{array}
$$

the model of time interval $\left[S, T_{0}\right]$ and $\left[T_{0}, T\right]$, respectively. The parameters $k_{0}, k_{1}$, and $k_{2}$ reflect the number of parameters. $L$ means the maximum likelihood of the ETAS model. Then, we compared the $\mathrm{AIC}_{0}$ with $\mathrm{AIC}_{1}+\mathrm{AIC}_{2}+2 q(N)$ (Ogata 1992). The term $q(N)$ is a penalty value (Ogata 1992, 1999). We set the value of $q(N)$ by using the results of Kumazawa et al. (2010). We then calculated the ETAS parameters for the two periods (Period I and Period II) (Table 2). When we calculated the ETAS parameter for the Pre time (from January 5, 1996, to February 2002) of Period I, the parameter $\alpha$ stayed at nearly zero. To avoid this, we fixed $\alpha$ at 1.0 for the Pre of Period I.

\section{Results}

\section{Long-term and short-term strain rate}

The long-term dilation and shear strain rate were off the stationary trend in 2002 and 2012-2013 (Fig. 5a). The long-term dilatation rate and the maximum shear stress 


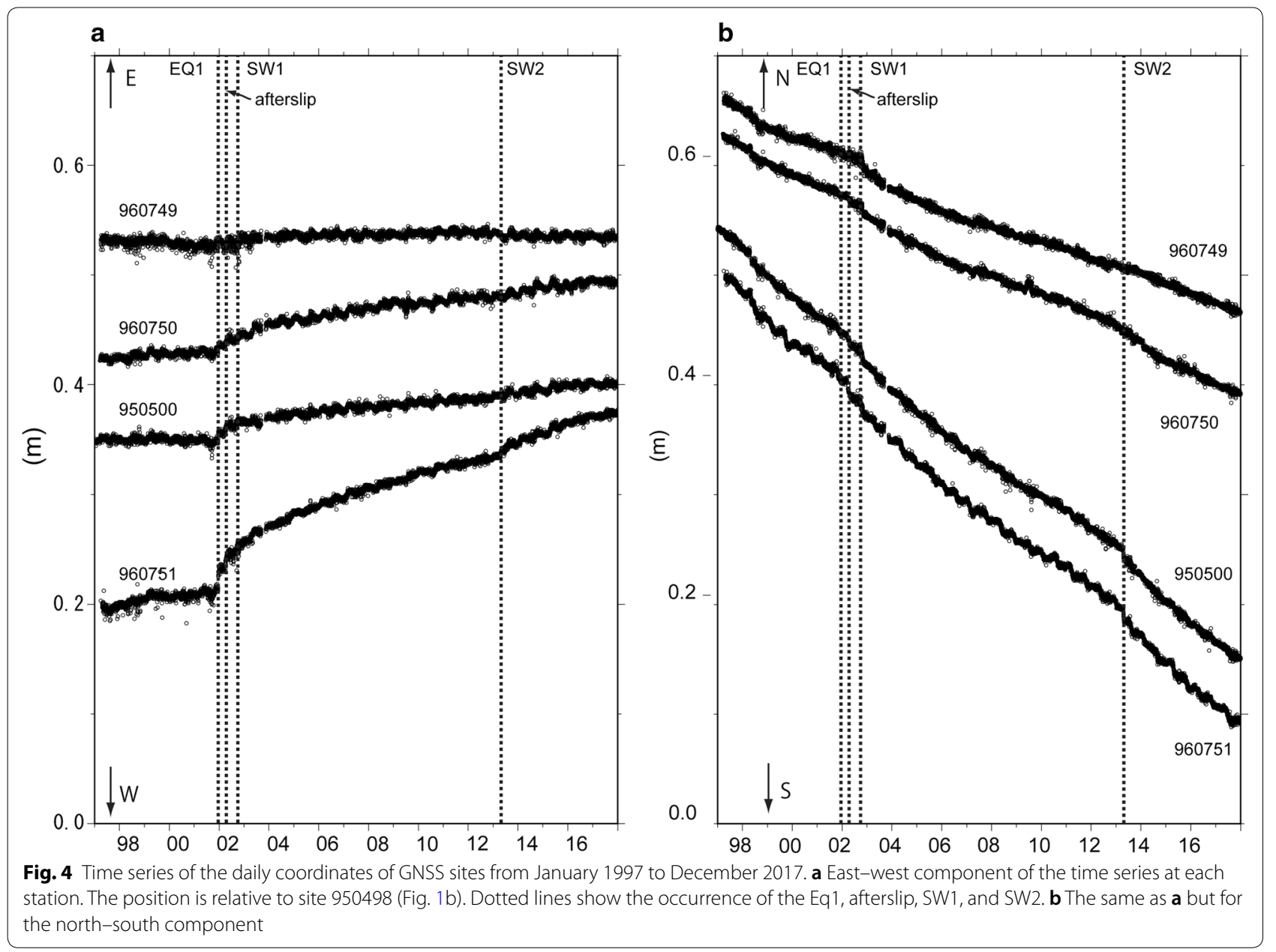

Table 1 Model parameters of the faults and dikes used in this study

\begin{tabular}{|c|c|c|c|c|c|c|c|c|c|c|}
\hline \multirow[t]{2}{*}{ Model } & \multicolumn{3}{|c|}{ Position of top center } & \multirow[t]{2}{*}{ Length (km) } & \multirow[t]{2}{*}{ Width (km) } & \multirow[t]{2}{*}{ Strike $\left({ }^{\circ}\right)$} & \multirow[t]{2}{*}{$\operatorname{Dip}\left({ }^{\circ}\right)$} & \multirow[t]{2}{*}{ Slip (cm) } & \multirow[t]{2}{*}{ Rake $\left(^{\circ}\right)$} & \multirow[t]{2}{*}{ Tensile (cm) } \\
\hline & Latitude (north) & Longitude (east) & Depth (km) & & & & & & & \\
\hline Eq1 & 23.95 & 122.80 & 15 & 15 & 15 & 210 & 60 & 150 & -120 & \\
\hline Afterslip & 24.18 & 123.12 & 35 & 80 & 30 & 280 & 30 & 150 & 135 & \\
\hline SW1 & 25.26 & 123.80 & 0 & 20 & 10 & 270 & 90 & & & 200 \\
\hline SW2 & 24.82 & 123.33 & 0 & 20 & 10 & 270 & 90 & & & 200 \\
\hline
\end{tabular}

rate were almost zero $\left(-0.003\right.$ to $0.006 \mathrm{ppm} \mathrm{year}^{-1}$ ) and $0.06 \mathrm{ppm}$ year $^{-1}$, respectively, from 1999 to 2001. The error of dilatation and shear strain rate was $0.043 \mathrm{ppm}_{\text {year }}{ }^{-1}$ and $0.028 \mathrm{ppm} \mathrm{year}^{-1}$, respectively. The extensional axis was in the northeast-southwest direction (Fig. 6). However, the degree of the dilatation rate increased to $0.014-0.10 \mathrm{ppm}$ year $^{-1}$ (Fig. 5a) and the direction of the extensional strain axis changed from the NE-SW to NNW-SSE direction between 2001 and 2004 (Fig. 6). The maximum shear strain rate also increased to $0.11 \mathrm{ppm} \mathrm{ear}^{-1}$ in 2002. After 2002, the dilatation rate and maximum shear strain rate decreased and were close to zero. The decreasing trend changed after 2012. After that time, the maximum shear stress rate increased to $0.064-0.070 \mathrm{ppm}_{\text {year }}{ }^{-1}$ at 2012-2013 (Fig. 5a). The dilatation rate changed to negative $\left(-0.009\right.$ to $\left.-0.055 \mathrm{ppm}_{\text {year }}{ }^{-1}\right)$, and the compressional stress for the WNW-ESE direction has been dominant since 2013 (Fig. 6). 
The short-term strain analysis revealed the dilatation rate change by repeating SSEs. The 3-month strain analysis showed that the peaks of the positive dilatation rate increased for every 6-month interval (Fig. 5b). The peaks of the positive dilatation rate correspond to the occurrence of the SSEs. The peaks of the dilatation rate were $0.2-0.4 \mathrm{ppm}_{\text {year }}{ }^{-1}$ (Fig. $5 \mathrm{~b}$ ), and the directions of the extensional strain rate were generally in the north-south direction. The short-term shear strain rate reached the peak when a SSE occurred. However, it sometimes reached a peak between the SSEs. In this period, the compressional strain for the N-S direction was dominant in the Yaeyama Islands, which suggests that this compressional strain rate corresponds to the accumulation of stress between the SSEs.

Observed short-term strain rates revealed differences in the strain accumulation between the SW1 and the SW2. When the SW1 occurred in the Okinawa Trough, a positive dilatation and large shear strain rate for the short-term was found in the Yaeyama Islands (Fig. 5b, c). However, since the SW1 occurred over the same term with the occurrence of the SSEs during the swarm, we cannot divide the strain caused by the SW1 with that caused by the SSEs from the short-term strain. On the other hand, when the SW2 occurred on April 2013 in the Okinawa Trough, the short-term dilatation rate in the Yaeyama Islands showed a small dilatational strain and large short-term shear strain rate (Fig. 5b, c).

\section{$\Delta$ CFS by the faulting and dike}

The computed results showed differences in strain and $\triangle$ CFS among the Eq1, 2002 afterslip, SW1, and SW2. Figure $7 \mathrm{~b}, \mathrm{~d}, \mathrm{f}, \mathrm{h}$ shows the $\triangle \mathrm{CFS}$ at the frictional coefficient of 0.2 . The computed extensional and compressional strain axis for the Eq1 was $\mathrm{N}-\mathrm{S}$ and $\mathrm{E}-\mathrm{W}$, respectively (Fig. 7a). The negative dilatation was dominant in the $\mathrm{S}$ region. The computed $\triangle$ CFS for the Eq1 in the $S$ region was -1 to $-10 \mathrm{kPa}$ (Fig. 7b). When the 2002 afterslip occurred, the positive dilatation was dominant in the $\mathrm{S}$ region (Fig. $7 \mathrm{c}$ ). The directions of the extensional and compressional strain axis, which were estimated by using the calculated displacement of GNSS sites, were NNWESE and ENE-WSW, respectively. The $\triangle \mathrm{CFS}$ in the $\mathrm{S}$ region for the 2002 afterslip was $10-100 \mathrm{kPa}$ (Fig. 7d). The negative dilatation was dominant in the $S$ region in the case of the SW1 (Fig. 7e). The directions of the extensional and compressional strain axis for the SW1 were $\mathrm{E}-\mathrm{W}$ and $\mathrm{N}-\mathrm{S}$, respectively. The $\triangle \mathrm{CFS}$ for the SW1 in the $\mathrm{S}$ region was -1 to $-10 \mathrm{kPa}$ (Fig. $7 \mathrm{f}$ ). The negative dilatation was dominant in the area south of Iriomote Island in the case of the SW2 (Fig. 5g). The directions of the extensional and compressional strain axis for the SW2 were NE-SW and NW-SE, respectively. The $\triangle \mathrm{CFS}$ for the SW2 in the S region was $1-10 \mathrm{kPa}$ (Fig. 7h). Although we changed the frictional coefficient of the $\triangle$ CFS from 0.0 to 0.6 , the distribution of the positive and negative $\triangle$ CFS only changed slightly (Additional file 1: Fig. S1).

\section{Seismicity}

Corresponding to the crustal deformation events of Period I and Period II, the change in seismicity in the area south of Iriomote Island was detected by change point analysis in ETAS (Fig. 8). For Period I, the seismicity rate was almost constant from January 1996 to December 2001. However, the seismicity rate increased starting in January 2002 (Figs. 3a, 8a). Around this time, an M4.7 earthquake occurred on December 21, 2001 (Fig. 8c). The $\triangle \mathrm{AIC}$ reached the maximum (16.37) in around January 2002 (Fig. 8e). The seismicity rate then returned to the previous state until around 2004-2005. The background seismicity increased from 0.0064 to 0.076 after February 2002 (Table 3).

For Period II, when the anomalous crustal deformation occurred on 2012-2013 (Fig. 6), the seismicity rate was activated starting in May 2013 (Figs. 3a, 8c). However, no remarkable earthquake accompanying the seismicity rate change was found (Fig. $8 \mathrm{~d}$ ). This seismicity activation has continued until late 2017. The $\triangle \mathrm{AIC}$ reached its maximum (11.9) in May 2013 (Fig. 8f). The background seismicity increased from 0.029 to 0.093 after May 2013 (Table 3).

\section{Discussion}

\section{Cause of the increased shear strain rate in $\mathbf{2 0 0 2}$}

The shear strain rate in the Yaeyama Islands increased in 2002. The directions of the extensional and compressional strain axis were consistent with those expected from the modified afterslip model (Fig. 7c). The estimated total shear strain from the modified afterslip model in the Yaeyama Islands was $0.93 \mathrm{ppm}$. The averaged shear strain by the afterslip from 2002-2005 was $0.2 \mathrm{ppm} \mathrm{year}^{-1}$. The observed annual strain rate from 2002 to 2005 was 0.03-0.1 ppm year ${ }^{-1}$ in the Yaeyama Islands (Fig. 5a). This is half to one-seventh of the computed one. This difference reflects the heterogeneity of the fault slip. The

Table 2 Earthquake catalog used in the analysis

\begin{tabular}{llllll}
\hline & $\boldsymbol{T}_{\text {start }}$ & $\boldsymbol{T}_{\mathbf{0}}$ & $\boldsymbol{T}_{\text {end }}$ & Mc & $\boldsymbol{N}$ \\
\hline Period I & $1996 / 01 / 05$ & $2002 / 01 / 26$ & $2002 / 12 / 18$ & 2.3 & 197 \\
& $19: 33$ & $11: 06$ & $02: 47$ & & \\
Period II & $2007 / 06 / 03$ & $2013 / 05 / 10$ & $2017 / 03 / 08$ & 2.0 & 334 \\
& $16: 34$ & $02: 02$ & $15: 18$ & & \\
\hline
\end{tabular}

Time is given by the date (YYYY/MM/DD) and time (hh:mm). $N$ is the number of events. $T_{0}$ means the time when the seismicity changed 

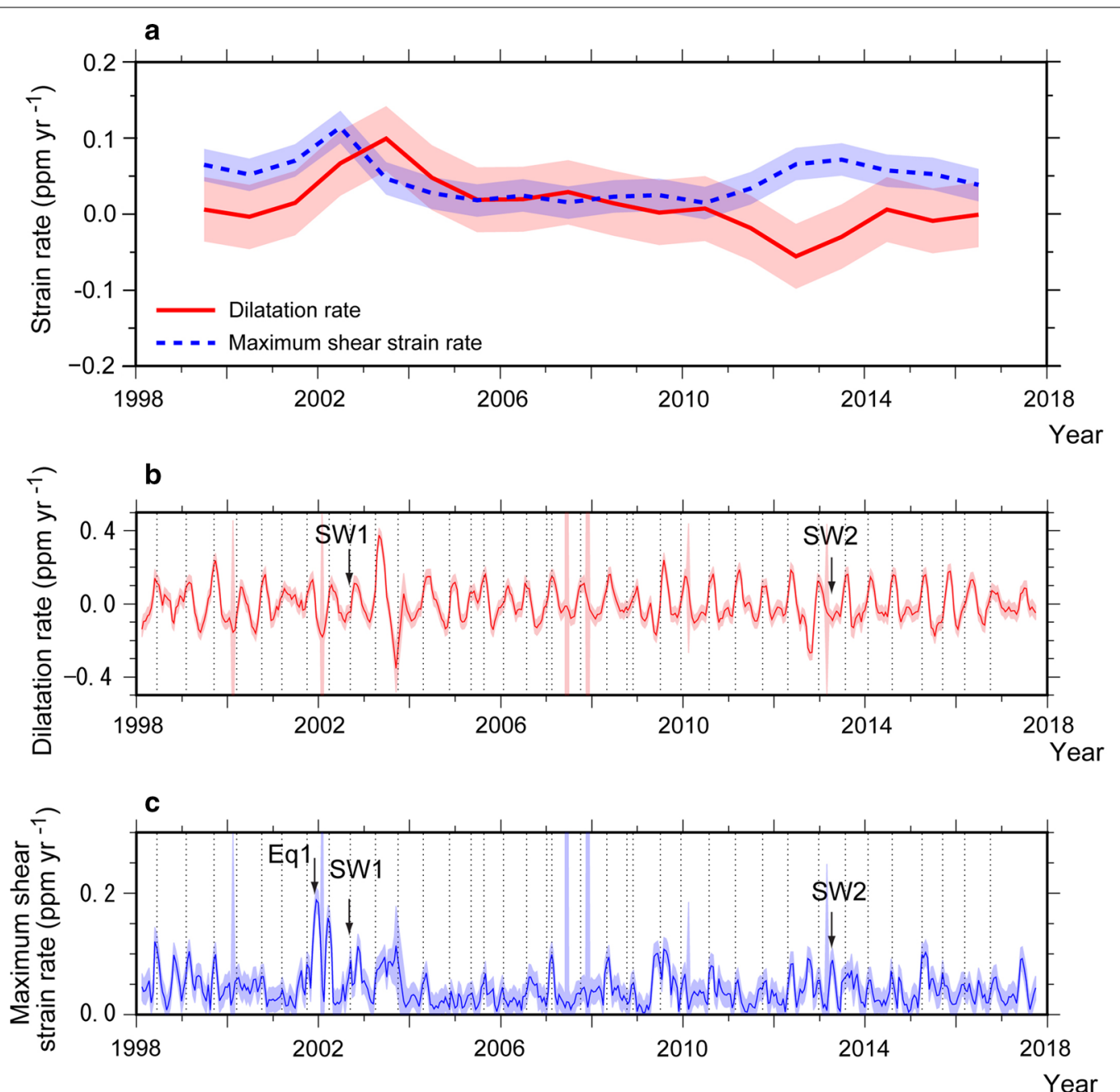

Fig. 5 Strain rate change in the Yaeyama Islands. a Averaged strain rate for 3 years in the Yaeyama Islands from 1999 to 2016. Red line and dotted blue line show the dilatation rate and maximum shear strain rate, respectively. Thin red and blue areas show the error range of the dilatation rate and maximum shear strain rate, respectively. b Averaged dilatation rate for 3 months in the Yaeyama Islands from 1998 to 2017. Red line shows the dilatation rate. The thin red area shows the error range of the dilatation rate. Dotted vertical lines show the occurrence of the SSEs by Tu and Heki (2017). c The same as $\mathbf{b}$ but for the maximum shear strain rate

area where the strain was computed and the seismicity changed is located in the east end and near the fault edge of the afterslip. We assumed a homogeneous slip distribution for the calculation of the strain. However, due to the actual afterslip faulting with heterogeneity, different strain distributions would have been generated in the south part of Iriomote Island. However, the positive $\triangle$ CFS of the modified afterslip model was consistent with the activated seismicity in the area south of Iriomote Island (Fig. 7d).

On the other hand, the modeled strain caused by the SW1 could not explain the observed 2002 strain field. The estimated directions of the strain axes for SW1 were inconsistent with the observed ones in the Yaeyama
Islands. The estimated $\triangle \mathrm{CFS}$ for the SW1 in the area south of Iriomote Island was also negative, which made it difficult to activate the seismicity (Fig. 7d). This suggests that the increased shear strain in 2002 was not caused by the dike intrusion; instead, it may have been caused mainly by the afterslip. Moreover, the post-seismic deformation of the visco-elasticity layer proceeds by the same trend as the coseismic deformation far from the fault (Hampel and Hetzel 2015). Thus, it was difficult to show that the compressional strain field during the dike intrusion changed to that of an extensional one after the event involving the visco-elasticity.

Similarly, the strain by the Eq1, which occurred in the southwest part of Iriomote Island during 2001, did 


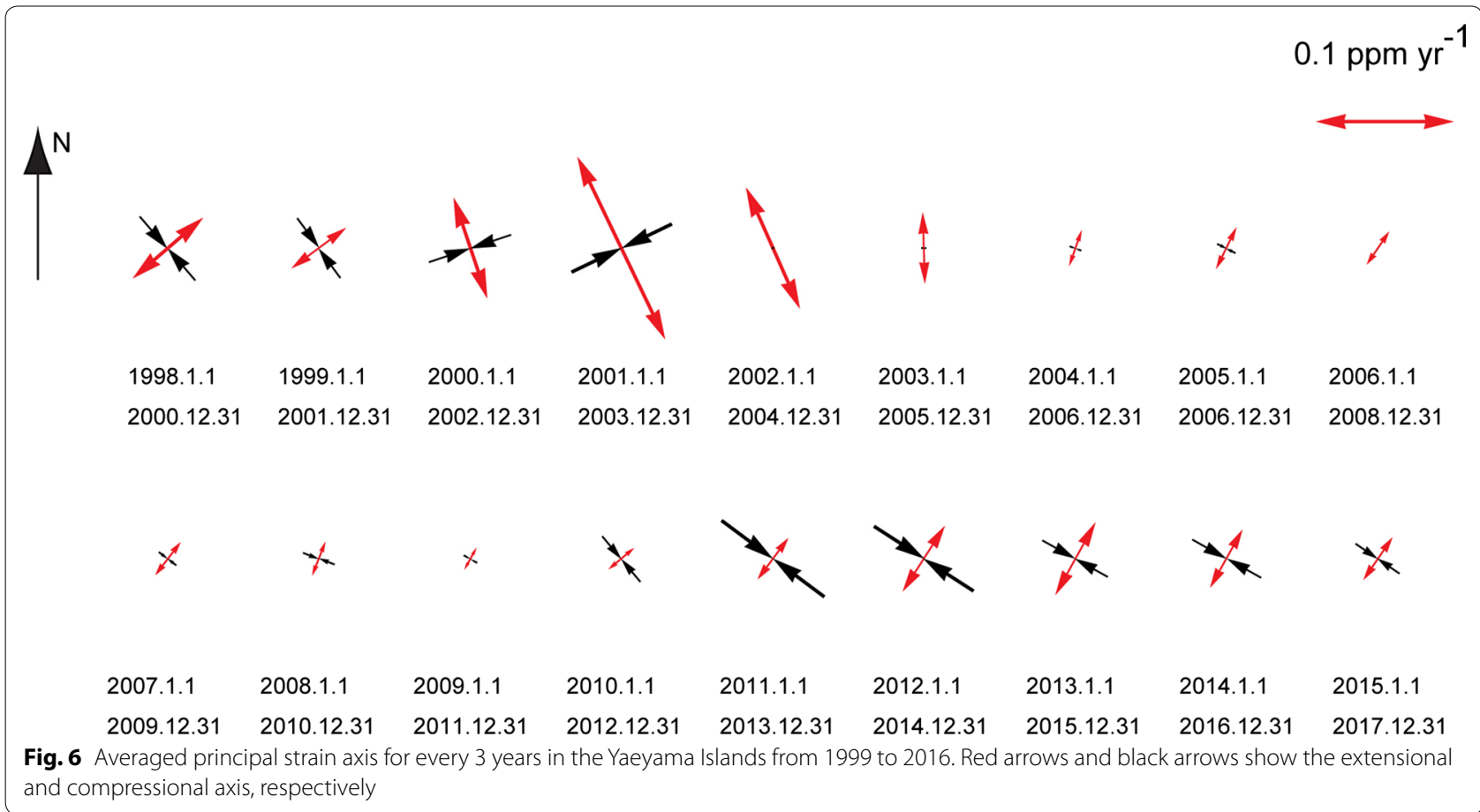

not affect the long-term strain rate and seismicity. The maximum peak of the short-term maximum shear strain rate, which was caused by the Eq1 and its afterslip, was detected in late 2001. The observed maximum shear strain rate was $0.2 \mathrm{ppm} \mathrm{year}^{-1}$ (Fig. 5c). The calculated maximum shear strain change caused by the Eq1 was on the order of $0.1 \mathrm{ppm}_{\text {year }}^{-1}$ (Fig. 7a). By adding the coseismic strain change with the afterslip of the Eq1 [30\% of the Eq1 (Nakamura 2009)], the maximum shear strain was estimated as $0.13 \mathrm{ppm}$ year $^{-1}$. This value was similar to the observed one, which suggests that this peak can be explained by using the displacement of the Eq1 and its afterslip. The afterslip of the Eq1 terminated in approximately 1 month (Nakamura 2009), and the degree of the strain rate caused by the Eq1 was on the order of onetenth of that caused by the 2002 afterslip and the SW1. This suggests that the coseismic displacement and afterslip of the Eq1 were too small to affect the long-term strain rate change. The $\triangle$ CFS by the Eq1 was negative in the southwest part of Iriomote Island, which is also inconsistent with the increased seismicity.

\section{Cause of the increased shear strain rate in 2013}

In contrast to the case of the 2002 strain rate change, the increased shear strain rate in 2012-2013 was generated by a dike intrusion. In the case of the 2013 event, the observed strain field was compressional. The observed extensional and compressional axis was in the SSW-NNE direction and WNW-ESE direction, respectively (Fig. 6). This was consistent with the estimated strain field by the SW2 model (Fig. 7e). The positive $\triangle C F S$ near Iriomote Island was also consistent with the activated seismicity after 2013. The high shear strain rate has been gently decreasing from $0.08 \mathrm{ppm}$ year $^{-1}$ but has remained at a high value of 0.03-0.08 ppm year ${ }^{-1}$ since 2013 (Fig. 5a). The value of the strain rate of 2014 reflects the post-SW 2 crustal movement and does not contain the deformation accompanying the SW2. This deformation might have been caused by the post-seismic deformation induced by the dike intrusion and the visco-elastic effect in the Okinawa Trough.

\section{Effect of the frictional coefficient on the $\triangle$ CFS distribution}

The calculation of the $\triangle C F S$ with changes in the frictional coefficient showed that the difference in distribution of the $\triangle \mathrm{CFS}$ for different frictional coefficients was small except in the vicinity of the fault or dike (Fig. 7 and Additional file 1: Fig. S1). This suggests that the effect for changing the frictional coefficient was relatively small because the normal stress change was smaller than the shear stress change except near the faults and dikes. On the other hand, the distribution of the $\triangle$ CFS changed near the faults and dikes. In this calculation, the normal stress change was larger than the shear stress change near the fault and dike.

In the case of the dike intrusion in the Okinawa Trough, which occurred far from the area southwest of 
Iriomote Island, the different frictional coefficients only had a small effect on the $\triangle \mathrm{CFS}$ in the area southwest of Iriomote Island. In the case of the afterslip, since the source fault was located in the southwest part of Iriomote Island, the distribution of the positive $\triangle \mathrm{CFS}$ area changed with different frictional coefficients. However, almost the entire region in the area southwest of Iriomote Island was positive with the different frictional coefficients. These results suggest that the effect of the difference of frictional coefficient was small for the $\triangle \mathrm{CFS}$ in the area southwest of Iriomote Island.

\section{Relationship between the seismicity change and strain rate change}

The activated seismicity during the increase in the shear strain rate was observed twice after 1995 in the S region. In the case of Period I, the seismicity activation started approximately 2 months before the start of the 2002 afterslip. However, high $\triangle \mathrm{AIC}$ values continued to the beginning of April, which marked the start of the afterslip (Fig. 8e). This suggests that the timing of the seismicity change would be almost the same as that of the start of afterslip. This suggests that the seismicity had increased mainly in conjunction with the change in the strain rate caused by the afterslip. In the case of Period II, the activation of the seismicity coincided ( $\sim 1$ month) with the occurrence of the SW2, which occurred in the Okinawa Trough in April 2013. This suggests that the seismicity activation for Period II was caused by the SW2.

The rate of the SSEs beneath Iriomote Island also increased in 2002 and 2013 (Tu and Heki 2017). These rate changes were caused by different crustal movements, which affected the Yaeyama Islands. The 2002 afterslip induced the crust near Iriomote Island to move southward, which increased the SSE rate. The inducement in the SSE rate since 2013 could have been caused by the intrusion of the dike, which pulled the crust near Iriomote Island southward.

The change in seismicity for the stress change was formulized by Dieterich (1994). According to that work, because of the sudden stress change within a period of several days, the seismicity increased abruptly and then decreased gradually to the steady-state level (Dieterich 1994; Toda et al. 2002; Lohman and McGuire 2007). On the other hand, for the stressing rate change continuing on the order of 1 month, the seismicity started to increase for several months, and high seismicity conditions continued during the high stressing rate (Toda et al. 2002). The activity of the 2002 afterslip event continued for several years, which corresponds to the long-term stressing rate change. In this case, the seismicity would have continued to increase during several months and high seismicity continued while the faulting of the afterslip continued.

However, since the SW2 continued over several days to several weeks, the seismicity would have been higher for several weeks, and then, it decreased. However, decreased seismicity several weeks after the 2013 seismicity activation was not detected. This suggests that the increased seismicity of 2013 was not only related to the stressing rate change caused by the dike intrusion, but that it also contributed the long-term post-seismic deformation after the dike intrusion in the visco-elastic material.

\section{Conclusions}

The seismicity in the $\mathrm{S}$ region was found to be related to the long-term shear strain rate. The seismicity increased at a delay with the increased shear strain rate, and it lasted several years. This is consistent with the seismicity change, which was predicted from the rate and state frictional model (Dieterich 1994; Toda et al. 2002). The increase in the shear strain was not caused by one simple factor but was possibly related to the afterslip of large earthquakes in the Ryukyu arc and dike intrusion in the Okinawa Trough. In correspondence with changes in both of these processes, seismic activity in the $\mathrm{S}$ region increased. Although the shear strain rate has been decreasing since 2013, its value remains larger than that in 2008. This means that the seismicity has been activated since 2013. The M5.6 earthquake on March 2, 2018, in the area south of Iriomote Island might have been a part of the activated seismicity that began in 2013.

\footnotetext{
(See figure on next page.)

Fig. 7 Strain and $\triangle$ CFS by dike intrusion and faulting. a Dilatation by the Eq1 faulting at the depth of $0 \mathrm{~km}$. Red and blue arrows denote the theoretical extensional and compressional strain axis, respectively, which were calculated from the dike intrusion and faulting model. The white bold rectangle shows the fault of the Eq1. b $\triangle$ CFS at the depth of $15 \mathrm{~km}$ by the Eq1. c The same as a but for the 2002 afterslip. The notation at the right side of the panel shows the parameter of the receiver-side fault, which was used for the calculation of the $\Delta$ CFS. $\mathbf{d}$ The same as $\mathbf{b}$ but for the 2002 afterslip. e The same as a but for the SW1. The fault parameters (strike, dip, length, width, and degrees of intrusion) are the same as the SW2. The white circles show the epicenters of earthquakes $(M>2.0$ and depth $<30 \mathrm{~km})$ that occurred on October 2002. The black solid line shows the dike of the SW1. $\mathbf{f}$ The same as $\mathbf{b}$ but for the SW1. The white solid line shows the dike of the SW1. $\mathbf{g}$ The same as $\mathbf{a}$ but for the SW2. The open circles show the epicenters of earthquakes $(M>2.0$ and depth $<30 \mathrm{~km}$ ) that occurred on April 2013. The black solid line shows the dike of the SW2. $\mathbf{h}$ The same as $\mathbf{b}$ but for the SW2. The white solid line shows the dike of the SW2
} 

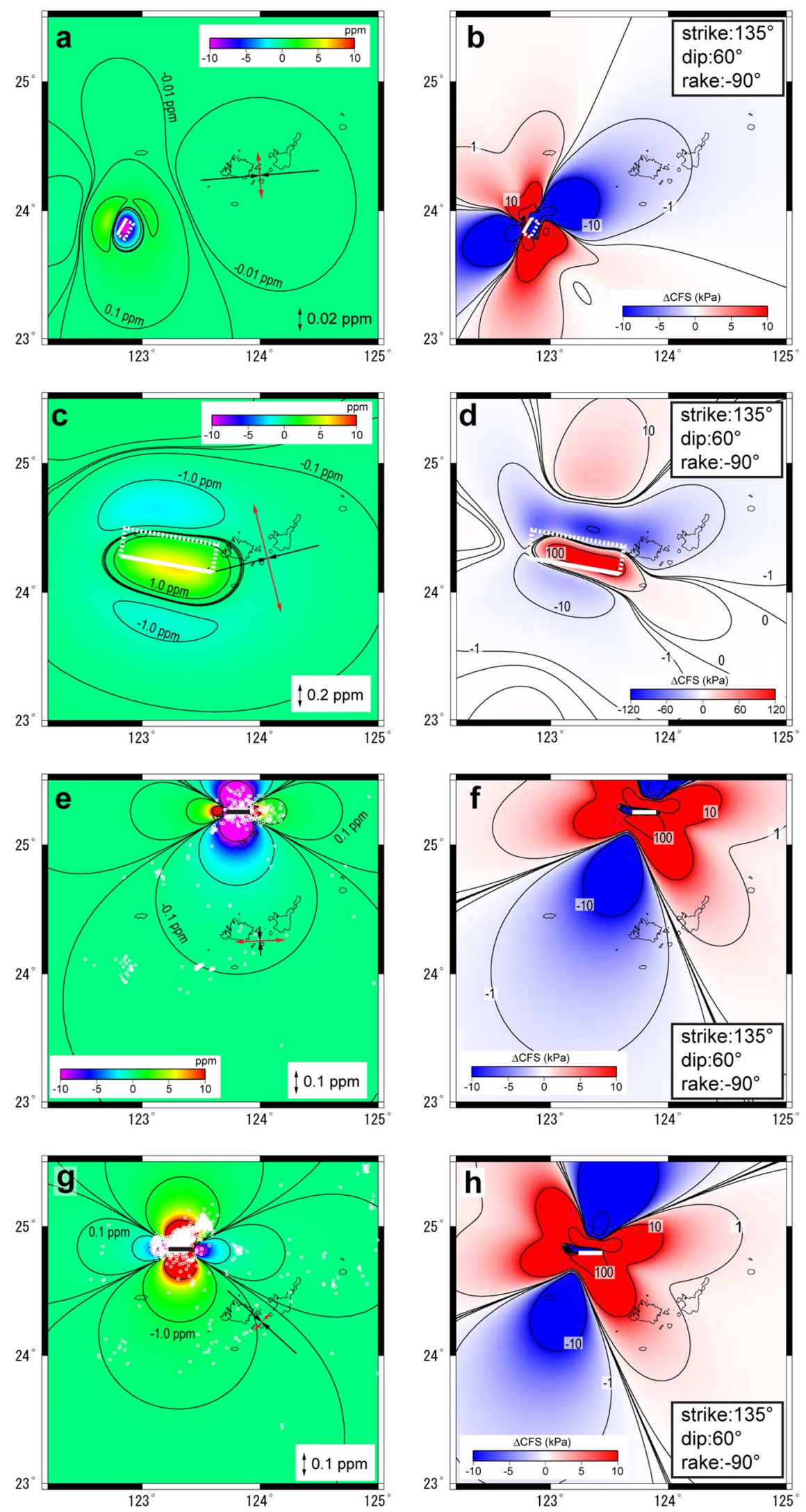


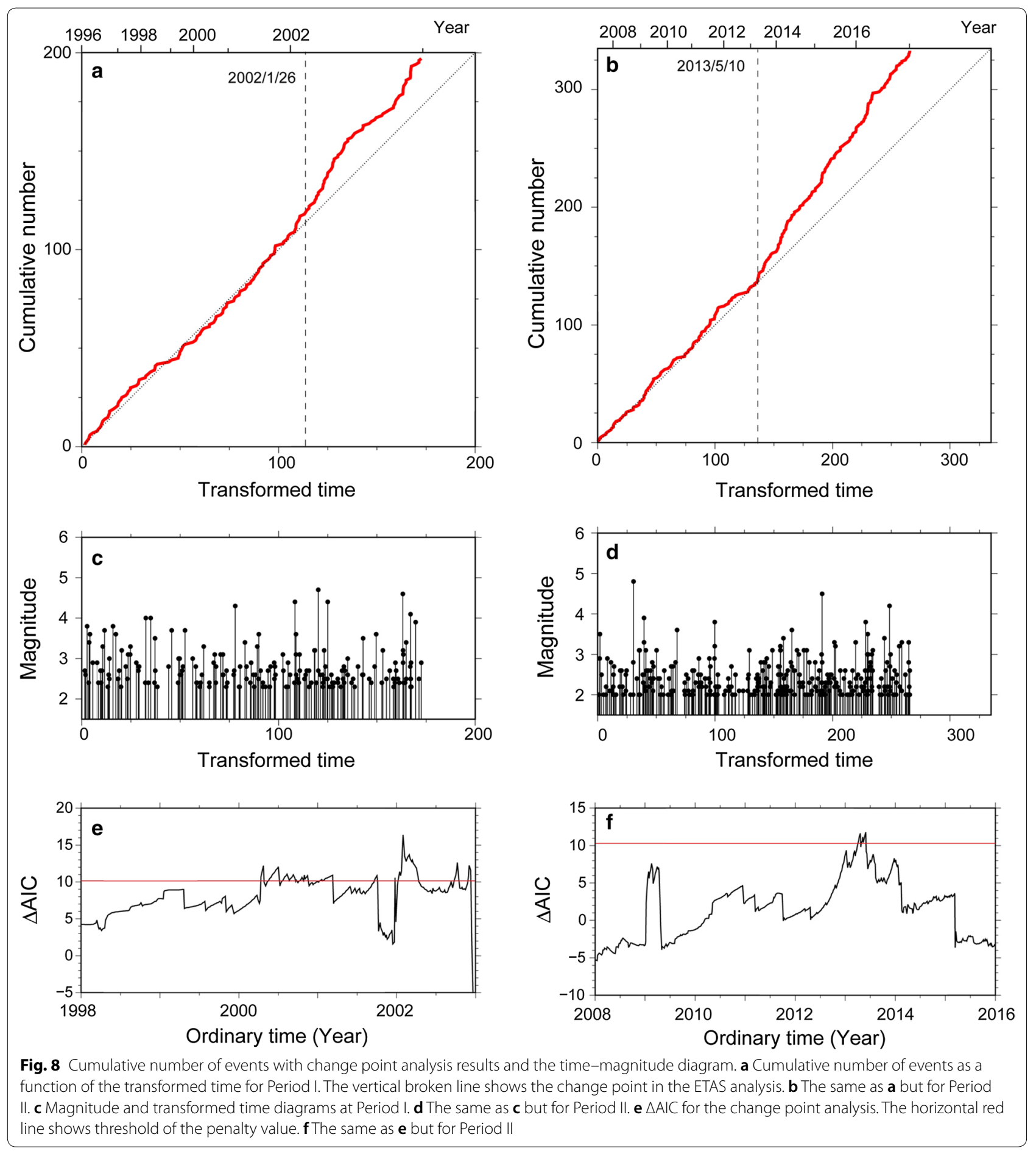

The results of this study suggest that the seismicity in the $S$ region responds sensitively to the strain changes caused by slow earthquakes in the surrounding area. The area south of Iriomote Island is located on the top edge of the fault associated with the SSEs, and it is also located near the top edge of the 2002 afterslip fault. If the state 
Table 3 Calculated ETAS parameters

\begin{tabular}{|c|c|c|c|c|c|c|c|c|}
\hline & & $\mu_{\mathrm{es}}$ & $K_{\text {es }}$ & c & $a$ & $p$ & $\begin{array}{l}\mathrm{AlC}_{0} \\
\mathrm{AIC}_{1}+\mathrm{AIC}_{2} \\
\Delta \mathrm{AIC}\end{array}$ & $2 q(N)$ \\
\hline \multirow[t]{3}{*}{ Period I } & Single & 0.0169 & 0.0578 & $1.79 \mathrm{E}-03$ & 1.35 & 0.876 & 1178.47 & 10.04 \\
\hline & Pre & 0.00639 & 0.0760 & $7.57 \mathrm{E}-03$ & $1.0^{\mathrm{a}}$ & 0.829 & 1162.11 & \\
\hline & Post & 0.0767 & 0.0205 & $4.31 \mathrm{E}-03$ & 2.23 & 1.443 & 16.37 & \\
\hline \multirow[t]{3}{*}{ Period II } & Single & 0.0263 & 0.0824 & $7.50 \mathrm{E}-04$ & 1.13 & 0.833 & 2047.13 & 10.38 \\
\hline & Pre & 0.0291 & 0.0496 & $3.86 E-04$ & 1.06 & 0.798 & 2035.25 & \\
\hline & Post & 0.0932 & 0.0757 & $3.29 \mathrm{E}-03$ & 1.47 & 1.07 & 11.9 & \\
\hline
\end{tabular}

Single means the period between $T_{\text {start }}$ and $T_{\text {end }}$ (Table 1). Pre means the period between $T_{\text {start }}$ and $T_{0}$. Post means the period between $T_{0}$ and $T_{\text {end }}$

a Fixed

of faulting in the slow earthquake area changed, it would influence the seismicity around Iriomote Island through the strain change. This would contribute to crustal movement in the seismogenic zone of the subducting plate, which would be hard to detect by using GNSS.

\section{Additional file}

Additional file 1: Figure S1. $\triangle$ CFS by dike intrusion and faulting. a $\triangle$ CFS at the depth of $15 \mathrm{~km}$ by the $\mathrm{Eq} 1$ at a frictional coefficient of 0.0 . The white bold rectangle shows the fault of the Eq1. $\mathbf{b}$ The same as $\mathbf{a}$ but for a frictional coefficient of 0.6. $\mathbf{c}$ The same as $\mathbf{a}$ but by the afterslip. The white bold rectangle shows the fault of the afterslip. $\mathbf{d}$ The same as $\mathbf{c}$ but for a frictional coefficient of 0.6. e The same as a but by the SW1. The white solid line shows the dike of the SW1. fThe same as e but for a frictional coefficient of 0.6. $\mathbf{g}$ The same as $\mathbf{a}$ but by the SW2. $\mathbf{h}$ The same as $\mathbf{g}$ but for a frictional coefficient of 0.6 .

\section{Abbreviations}

AIC: Akaike information criterion; CMT: centroid moment tensor; CFS: difference in Coulomb failure stress; ETAS: epidemic-type aftershock sequence; Eq1: December 18, 2001, earthquake; EU: Eurasian plate; GEONET: GPS Earth Observation Network; GNSS: global navigation satellite system; GSI: Geospatial Information Authority of Japan; JMA: Japan Meteorological Agency; Mc: magnitude completeness; NIED: National Research Institute for Earth Science and Disaster Resilience; PH: Philippine Sea plate; SSE: slow slip event; SW1: 2002 earthquake swarm; SW2: 2013 earthquake swarm.

\section{Authors' contributions}

MN performed the analysis of strain and seismicity and wrote the manuscript. AK assisted with the seismicity analysis. Both authors read and approved the final manuscript.

\section{Acknowledgements}

We used the earthquake catalog compiled by the JMA and continuous GNSS data of GEONET from the GSI. We used the CMT catalog of Fnet provided by the NIED. We used the software "etas_solve" (Kasahara et al. 2016), "ZMAP" (Wiemer 2001), and subroutine package "DC3D" (Okada 1992). The plate models by Iwasaki et al. (2015) were constructed with topography and bathymetry data from the GSI (250-m digital map), Japan Oceanographic Data Center (500-m mesh bathymetry data, J-EGG500, http://www.jodc.go.jp/jodcweb/ JDOSS/infoJEGG_j.html), and Geographic Information Network of Alaska, University of Alaska (Lindquist et al. 2004). We used Generic Mapping Tools (Wessel and Smith 1998) to construct the map. We thank two anonymous reviewers whose comments helped to improve and refine the manuscript significantly. This work was supported by JSPS KAKENHI Grant Number JP16H06473.
Competing interests

The authors declare that they have no competing interests.

\section{Availability of data and materials}

The data that support the findings of this study are available upon request from the corresponding author.

\section{Consent for publication}

Not applicable.

Ethics approval and consent to participate

Not applicable.

\section{Funding}

This work was supported by the Japan Society for the Promotion of Science (JSPS) through KAKENHI Grant Number JP16H06473.

\section{Publisher's Note}

Springer Nature remains neutral with regard to jurisdictional claims in published maps and institutional affiliations.

Received: 1 June 2018 Accepted: 18 September 2018

Published online: 26 September 2018

\section{References}

Ando M, Ikuta R, Tu Y, Chen HY, Lin CH (2015) The Apr 2013 earthquake swarm and dyke intrusion in the Okinawa trough. In: Paper presented at the Japan Geoscience Union Meeting, Chiba, Japan, May 27, 2015

Bird P (2003) An updated digital model of plate boundaries. Geochem Geophys Geosys 4(3):1027. https://doi.org/10.1029/2001GC000252

Dieterich J (1994) A constitutive law for rate of earthquake production and its application to earthquake clustering. J Geophys Res 99:2601-2618

Dieterich J, Cayol V, Okubo P (2000) The use of earthquakes rate changes as a stress meter at Kilauea volcano. Nature 408:457-460

Hampel A, Hetzel R (2015) Horizontal surface velocity and strain patterns near thrust and normal faults during the earthquake cycle: the importance of viscoelastic relaxation in the lower crust and implications for interpreting geodetic data. Tectonics 34:731-752. https://doi.org/10.1002/2014T C003605

Heki K, Kataoka T (2008) On the biannually repeating slow-slip events at the Ryukyu Trench, southwestern Japan. J Geophys Res 113:B11402. https:// doi.org/10.1029/2008JB005739

Iwasaki T, Sato H, Shinohara M, Ishiyama T, Hashima A (2015) Fundamental structure model of island arcs and subducted plates in and around Japan. 2015 Fall Meeting, American Geophysical Union, San Francisco, Dec. 14-18, T31B-2878

JMA (Japan Meteorological Agency) (2002) Records for the service of earthquake observations. Q J Seismol 65(Suppl.):64-69 (in Japanese) 
JMA (Japan Meteorological Agency) (2018) Seismic stations in the Ryukyu Islands. http://www.data.jma.go.jp/svd/egev/data/bulletin/catalog/ appendix/stokinaw.html. Accessed 12 April 2018

Kasahara A, Yagi Y, Enescu B (2016) etas_solve: a robust program to estimate the ETAS model parameters. Seismol Res Lett 87:1143-1149. https://doi. org/10.1785/0220150240

King GCP, Stein RS, Lin J (1994) Static stress changes and the triggering of earthquakes. Bull Seismol Soc Am 84(3):935-953

Kreemer C, Blewitt G, Klein EC (2014) A geodetic plate motion and global strain rate model. Geochem Geophys Geosys 15:3849-3889. https://doi org/10.1002/2014GC005407

Kubo A, Fukuyama E (2003) Stress field along the Ryukyu Arc and the Okinawa Trough inferred from moment tensors of shallow earthquakes. Tectonophysics 210:305-316. https://doi.org/10.1016/S0012-821X(03)00132-8

Kumazawa T, Ogata Y, Toda S (2010) Precursory seismic anomalies and transient crustal deformation prior to the $2008 \mathrm{Mw}=6.9$ Iwate-Miyagi Nairiku, Japan, earthquake. J Geophys Res 115:B10312. https://doi. org/10.1029/2010JB007567

Lindquist KG, Engle K, Stahlke D, Price E (2004) Global topography and bathymetry grid improves research efforts. Eos Trans AGU 85(19):186. https://doi.org/10.1029/2004EO190003

Llenos AL, McGuire JJ, Ogata Y (2009) Modeling seismic swarms triggered by aseismic transients. Earth Planet Sci Lett 281:59-69. https://doi. org/10.1016/j.epsl.2009.02.011

Lohman RB, McGuire JJ (2007) Earthquake swarms driven by aseismic creep in the Salton Trough, California. J Geophys Res 112:B04405. https://doi. org/10.1029/2006JB004596

Nakamura M (2004) Crustal deformation in the central and southern Ryukyu Arc estimated from GPS data. Earth Planet Sci Lett 217:389-398. https:// doi.org/10.1016/S0012-821X(03)00604-6

Nakamura M (2009) Aseismic crustal movement in southern Ryukyu Trench, southwest Japan. Geophys Res Lett 36:L20312. https://doi. org/10.1029/2009GL040357

Ogata Y (1988) Statistical models for earthquake occurrences and residual analysis for point processes. J Am Stat Assoc 83:9-27

Ogata Y (1992) Detection of precursory relative quiescence before great earthquakes through a statistical model. J Geophys Res 97:19845-19871

Ogata Y (1999) Seismicity analysis through point-process modeling: a review. Pure Appl Geophys 155:471-507
Okada Y (1992) Internal deformation due to shear and tensile faults in a halfspace. Bull Seismol Soc Am 82:1018-1040

Okutani T, Ide S (2011) Statistic analysis of swarm activities around the Boso Peninsula, Japan: slow slip events beneath Tokyo Bay? Earth Planets Space 63:419-426. https://doi.org/10.5047/eps.2011.02.010

Ozawa S, Suito H, Tobita M (2007) Occurrence of quasi-periodic slow-slip off the east coast of the Boso peninsula, Central Japan. Earth Planets Space 59:1241-1245. https://doi.org/10.1186/BF03352072

Sagiya T, Miyazaki S, Tada T (2000) Continuous GPS array and present-day crustal deformation of Japan. Pure Appl Geophys 157:2303-2322. https:// doi.org/10.1007/PL00022507

Segall P, Desmarais EK, Shally D, Miklius S, Cervelli P (2006) Earthquakes triggered by silent slip events on Kilauea volcano, Hawaii. Nature 442:71-74. https://doi.org/10.1038/nature04938

Shen AK, Jackson DD, Ge BX (1996) Crustal deformation across and beyond the Los Angeles basin from geodetic measurements. J Geophys Res 101:27957-27980

Toda S, Stein RS, Sagiya T (2002) Evidence from the AD 2000 Izu islands earthquake swarm that stressing rate governs seismicity. Nature 419:58-61

Tu Y, Heki K (2017) Decadal modulation of repeating slow slip event activity in the southwestern Ryukyu Arc possibly driven by rifting episodes at the Okinawa Trough. Geophys Res Lett 44:9308-9313. https://doi. org/10.1002/2017gl074455

Wessel P, Smith WHF (1998) New, improved version of generic mapping tools released. EOS Trans AGU 79:579. https://doi.org/10.1029/98EO00426

Wiemer S (2001) A software package to analyze seismicity: ZMAP. Seismol Res Lett 72:373-382. https://doi.org/10.1785/gssrl.72.3.373

Wiemer S, Wyss M (2000) Minimum magnitude of completeness in earthquake catalogs: examples from Alaska, the Western United States, and Japan. Bull Seismol Soc Am 90:859-869

Wolfe CJ, Brooks BA, Foster JH, Okubo PG (2007) Microearthquake streaks and seismicity triggered by slow earthquakes on the mobile south flank of Kilauea Volcano, Hawaii. Geophys Res Lett 34:L23306. https://doi. org/10.1029/2007GL031625

\section{Submit your manuscript to a SpringerOpen ${ }^{\circ}$ journal and benefit from:}

- Convenient online submission

- Rigorous peer review

- Open access: articles freely available online

- High visibility within the field

Retaining the copyright to your article

Submit your next manuscript at springeropen.com 